\title{
North-South surgical training partnerships: a systematic review
}

\author{
Tim Greive-Price MD \\ Hardee Mistry \\ Robert Baird, MDCM
}

Accepted Jan. 7, 2020

\author{
Correspondence to: \\ Robert Baird \\ Division of Pediatric General and \\ Thoracic Surgery \\ ACB Rm K0-134 \\ BC Children's Hospital \\ 4480 Oak St \\ Vancouver BC V6H 3V4 \\ robert.baird@cw.bc.ca
}

DOI: $10.1503 /$ cjs.008219
Background: Fostering the success of surgical trainees from low- and middle-income countries (LMICs) plausibly addresses the existing workforce deficit in a sustainable manner, but it is unclear whether and how these trainees are targeted as strategic learners for educational exchanges. The purpose of this review was to assess the quality and outcomes of existing literature on exchanges of surgical trainees between high-income countries (HICs) and LMICs.

Methods: We conducted a systematic review of reported instances of surgical training exchanges between HICs and LMICs. After database searching, 2 independent reviewers evaluated titles, abstracts and manuscripts. Selected studies were critically appraised with the use the Critical Assessment Skills Programme Qualitative Checklist and analyzed for trainee level, institutions, countries and subspecialties, as well as reported outcomes of the exchange.

Results: Twenty-eight reports met the inclusion criteria and were analyzed. Most publications (18 [64\%]) detailed North-to-South exchanges; 1 exchange was bidirectional. General surgery was the most common discipline identified, with 9 other subspecialties described involving learners at all phases of training. Reports were generally of good quality, although outcomes were reported variably, and most authors failed to acknowledge the ethical implications of their study.

Conclusion: The articles identified described a variety of surgical exchanges across disciplines, learner types and host/home countries. Few of the exchanges prioritized the learning of surgical trainees from LMICs. There is an increasing need to formalize these exchanges via clear goals and objectives, as well as to prioritize the proper matching of educational goals with local clinical needs.

Level of evidence: $\mathrm{V}$ - Evidence from systematic reviews of descriptive and qualitative studies.

Contexte : Le soutien à la réussite des chirurgiens en formation des pays à revenu faible ou moyen (PRFM) pourrait concrètement aider à remédier au manque d'effectifs actuel de façon durable. On ignore toutefois si ces apprenants sont ciblés par les programmes d'échanges en tant que candidats stratégiques et quelles sont les méthodes de recrutement employées. La présente revue vise à évaluer la qualité et les résultats des publications sur les échanges entre pays à revenu élevé (PRE) et PRFM auxquels participent des chirurgiens en formation.

Méthodes : Nous avons procédé à une revue systématique des cas rapportés d'échanges étudiants en chirurgie entre PRE et PRFM. Après une recherche dans les bases de données, 2 évaluateurs indépendants ont passé en revue les titres, les résumés et les manuscrits retenus. Les études sélectionnées ont fait l'objet d'une évaluation critique d'après la liste de contrôle pour la recherche qualitative CASP (Critical Assessment Skills Programme Qualitative Checklist); les critères d'analyse comprenaient le niveau de scolarité des apprenants, les établissements, les pays et les surspécialités, ainsi que les résultats rapportés pour l'échange.

Résultats : Au total, 28 rapports répondaient aux critères d'inclusion et ont donc été analysés. La plupart d'entre eux (18 [64\%]) traitaient d'échanges du nord au sud; un échange était bidirectionnel. La chirurgie générale était la discipline la plus souvent recensée; on a aussi décrit la participation d'apprenants à différentes étapes de leur formation pour 9 autres surspécialités. Les rapports étaient en général de bonne qualité, mais la présentation des résultats variait, et la majorité des auteurs ont omis de rendre compte des considérations éthiques de leur étude.

Conclusion : Les articles évalués décrivaient des échanges étudiants en chirurgie se rapportant à une multitude de disciplines, de types d'apprenants et de pays d'origine et d'accueil. Peu de programmes d'échanges priorisaient l'apprentissage des chirurgiens en formation issus des PRFM. Il est de plus en plus pressant de baliser les échanges étudiants en établissant des buts et des objectifs clairs, et de faire une priorité de la juste correspondance des objectifs pédagogiques et des besoins cliniques locaux.

Niveau de preuve : V — Preuve issue de revues systématiques d'études descriptives et qualitatives. 
$\mathbf{T}$ he delivery of surgical care to underresourced areas has been increasingly prioritized by health care providers and governing bodies, as evidenced by the efforts of the Lancet Commission on Global Surgery and the proliferation of organizations designed to address the existing burden of surgical disease. ${ }^{1-4}$ Capacity building has been recognized as a means of reaching tangible metrics of safe, timely and affordable care, with workforce limitations identified as a key barrier. ${ }^{5,6}$ Efforts to address this barrier through training programs for nurses, surgical/anesthesia trainees and attending physicians have been described. ${ }^{7-9}$ These and other initiatives clearly have laudable aims, but it is unclear to what degree trainees from low- and middleincome countries (LMICs, or "South") and educational exchanges are used strategically to address disparities in surgical care capacity. Although guidelines for short-term surgical missions with educational components have been published,${ }^{10}$ the likeliest key to addressing the considerable burden of unmet surgical need is through the support of embedded training programs and cultivation of the enormous potential of local surgeons-in-waiting. Educational exchanges or partnerships between high-income countries (HICs, or "North") and LMICs may complement existing programs but have been poorly characterized to date.

The purpose of the present study was to conduct a systematic review of reported instances of surgical training exchanges between HICs and LMICs, and evaluate the quality and characteristics of these reports. The inherent hypothesis is that there remains an asymmetric relation between institutions, with trainees more frequently moving from North to South.

\section{Methods}

Our study protocol, conduct and reporting of the review were in accordance with Preferred Reporting Items of Systematic Reviews and Meta-analyses (PRISMA). ${ }^{11}$

\section{Search strategy}

We conducted a systematic review of the literature, searching the following online databases: Ovid MEDLINE, Embase, EBM Reviews, CAB Direct, Web of Science, LILACS and PapersFirst. All languages were included, and there were no restrictions on publication dates. The search excluded publications from nonsurgical disciplines, animal/ basic science studies and editorials. In addition, we reviewed the complete list of references from all included studies and from publications that cited included studies, and retrieved relevant articles for analysis (snowballing and reverse snowballing, respectively).

The search strategy was designed in keeping with the PICOS (population, intervention, control, outcomes) format as follows: our population of interest was international exchanges of surgical trainees; our intervention consisted of exchanges occurring from LMICs to HICs or bidirectionally; our control consisted of traditional HIC-to-LMIC exchanges; and our outcomes included the effectiveness of such exchanges, the types of outcomes and metrics reported, and publication quality. The included study designs included case and observational studies (both prospective and retrospective), reviews and narratives (provided they included sufficient original data and measured outcomes). The complete search strategy, which was developed in collaboration with a senior hospital librarian, is presented in Appendix 1 (available at canjsurg.ca/008219-a1).

Publications were considered eligible if they described a specific, established program engaged in a uni- or bidirectional exchange of trainees in a surgical discipline. Trainees had to have travelled from an LMIC to a HIC, or vice versa; exchanges that did not involve at least 1 LMIC were excluded. For the purposes of this study, LMICs and HICs were based on classifications provided by the World Bank, where LMICs encompass all lowincome, lower-middle-income, and upper-middle-income economies. ${ }^{12}$ Trainees were defined as residents, fellows or medical students at the time of the exchange. Publications involving attending physicians were considered acceptable, provided the physicians was a generalist physicians (e.g., general practitioner, medical officer, community general surgeon) receiving (sub)specialist training in a surgical discipline; established, practising subspecialists were excluded. No restrictions were placed on the number of trainees in a given publication, as we aimed to capture reports from both HICs and LMICs, and sending large numbers of trainees may be financially limiting in LMICs. Publications were excluded if they did not present quantitative or qualitative outcomes regarding the trainees or their programs.

\section{Study screening and appraisal}

We compiled and managed publications using Rayyan software (http://rayyan.qcri.org). Duplicates were removed. Two reviewers (T.G.-P, H.M.) initially independently screened the same 100 publications, using titles and abstracts only. There were 11 discrepancies in the 200 independent observations between the 2 reviewers, yielding a screening $\mathrm{K}$ statistic of 0.80 (95\% confidence interval 0.691-0.915), which suggested substantial agreement. In case of discrepancies, consensus was obtained by discussion, or the discrepancy was arbitrated by the senior author. The reviewers then performed a first screen of all publications using title and abstract only. Subsequently, they performed a full-text evaluation of the remainder of the publications, based on the eligibility criteria.

We assessed the methodologic quality of articles that met the inclusion criteria using the Critical Appraisal Skills Programme Qualitative Checklist tool (Appendix 1). ${ }^{13}$ Each of the 10 questions is answered as "Yes," "Can't tell" or "No." 


\section{Study synthesis}

We created a data-extraction template to capture all pertinent information from each study. The following information was extracted from included articles: title, author, year of publication, study design, number and type of trainees, duration of exchange, home and host country of the exchange/program, program description, any reported outcomes and any sources of funding for the exchange. We subsequently evaluated comparative themes qualitatively.

\section{Results}

The search strategy returned 2304 results (Fig. 1). Duplicates were removed, leaving 1766 studies. After titles and abstracts were reviewed, 125 articles were extracted for full-text review. Twenty-eight publications were ultimately included in the analysis after full-text review. ${ }^{14-41}$

The 28 papers identified are summarized in Table 1 . The studies represent 8 unique HICs and 21 LMICs, with 18 exchanges occurring North to South, 6 occurring South to North, 3 occurring South to South and 1 truly bidirectional exchange in which trainees from Canada and Kenya spent time in each other's countries. ${ }^{14}$ Figure 2 shows the countries containing home and host institutions. Ten differ-

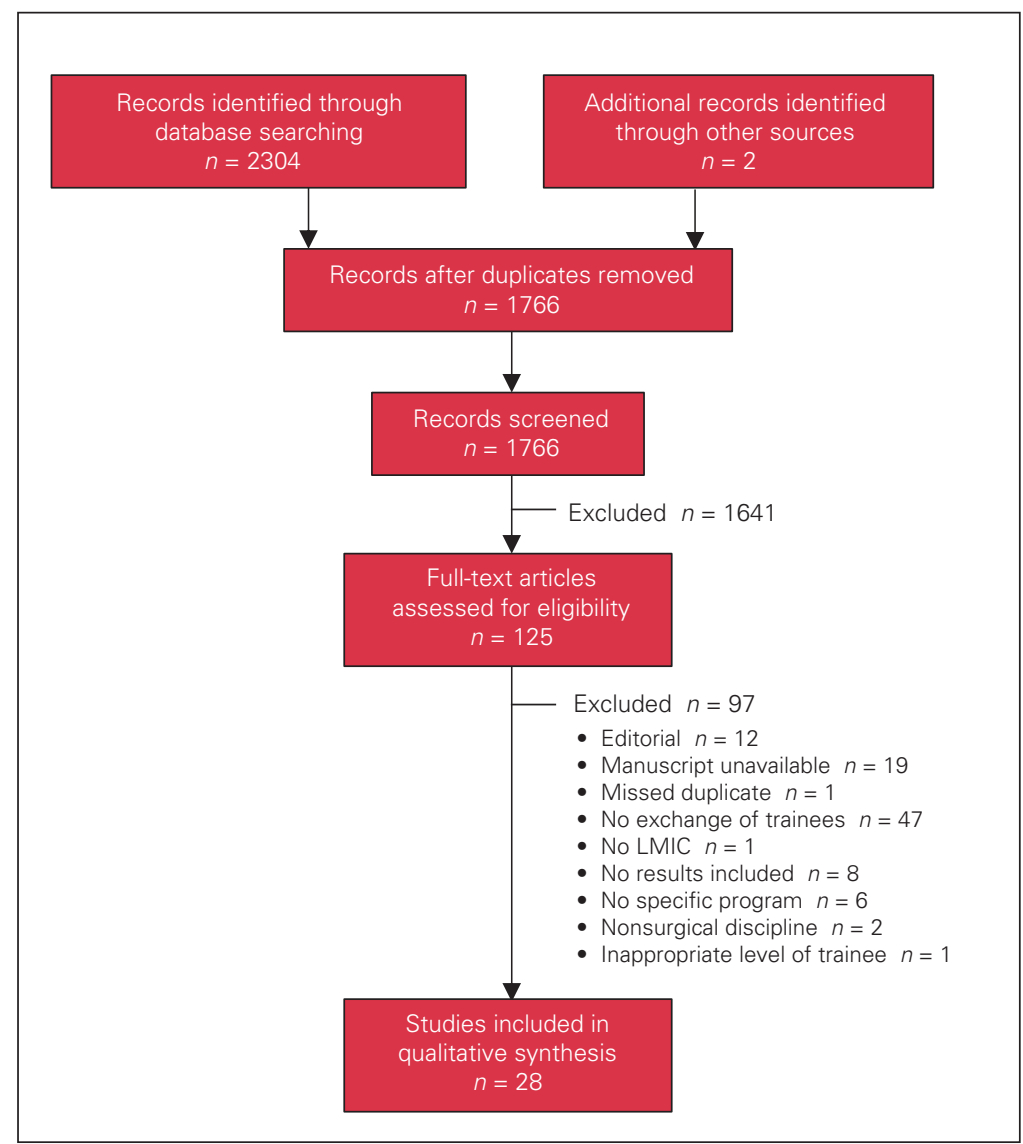

Fig. 1. Flow diagram showing selection of articles included in review. LMIC = low- or middle-income country. ent surgical specialties were represented a variable number of times: general surgery (16), pediatric surgery (4), plastic surgery (4), neurosurgery (3), obstetrics and gynecology (3), ophthalmology (3), urology (2), pediatric cardiac surgery, (1) orthopedic surgery (1) and otorhinolaryngology (1).

North-to-South exchanges were shorter in duration, on average, than other exchanges and consisted primarily of humanitarian surgical missions (7 exchanges) or rotations/ electives during residency (6 exchanges). Two programs described training local LMIC surgical trainees alongside visiting HIC trainees. There were also 4 instances in which a trainee from a HIC completed the entirety of his or her residency or fellowship in an LMIC. South-to-North programs were primarily rotations or specialized training programs meant to be supplementary components of residency/training programs completed in the trainees' home countries. The 1 bidirectional exchange followed a similar format, with pediatric surgery fellows from Kenya spending 6 weeks in Canada, and the Canadian fellows spending 4 weeks in Kenya; it comprised both service and educational components for all trainees. ${ }^{14}$ Two studies described facilitation of exchanges to HICs by LMIC governments for short-term training ${ }^{38}$ or for the entire graduate medical education, ${ }^{36}$ on the condition that the trainees return and practise in their home country. The South-toSouth exchanges included 1 subspecialist fellowship in renal transplantation and 2 neurosurgical conferences/courses attended by trainees from multiple LMICs in the same region.

Sixteen studies reported operative case numbers of their trainees or teams or both, 11 of which provided further breakdown of cases by discipline or specific operations. All operative data were reported in North-to-South and South-toSouth exchanges and the bidirectional exchange; no operative numbers were provided for Southto-North exchanges. The personal and professional development of trainees was reported in various forms in 18 publications, usually accomplished by means of a survey or, in cases in which there was only 1 trainee, with a descriptive report. Conduct of research activities in conjunction with the exchange was reported in 9 articles.

Four articles on South-to-North exchanges reported on the current status of the trainees after completion of the exchange (i.e., where they were practising and in what capacity), and all 4 stated that all or nearly all of their trainees had returned and were practising in their home country. $33,36-38$

\section{Quality of evidence}

Figure 3 illustrates trends across the included articles for the various qualities of qualitative research. Most publications were clear in their 


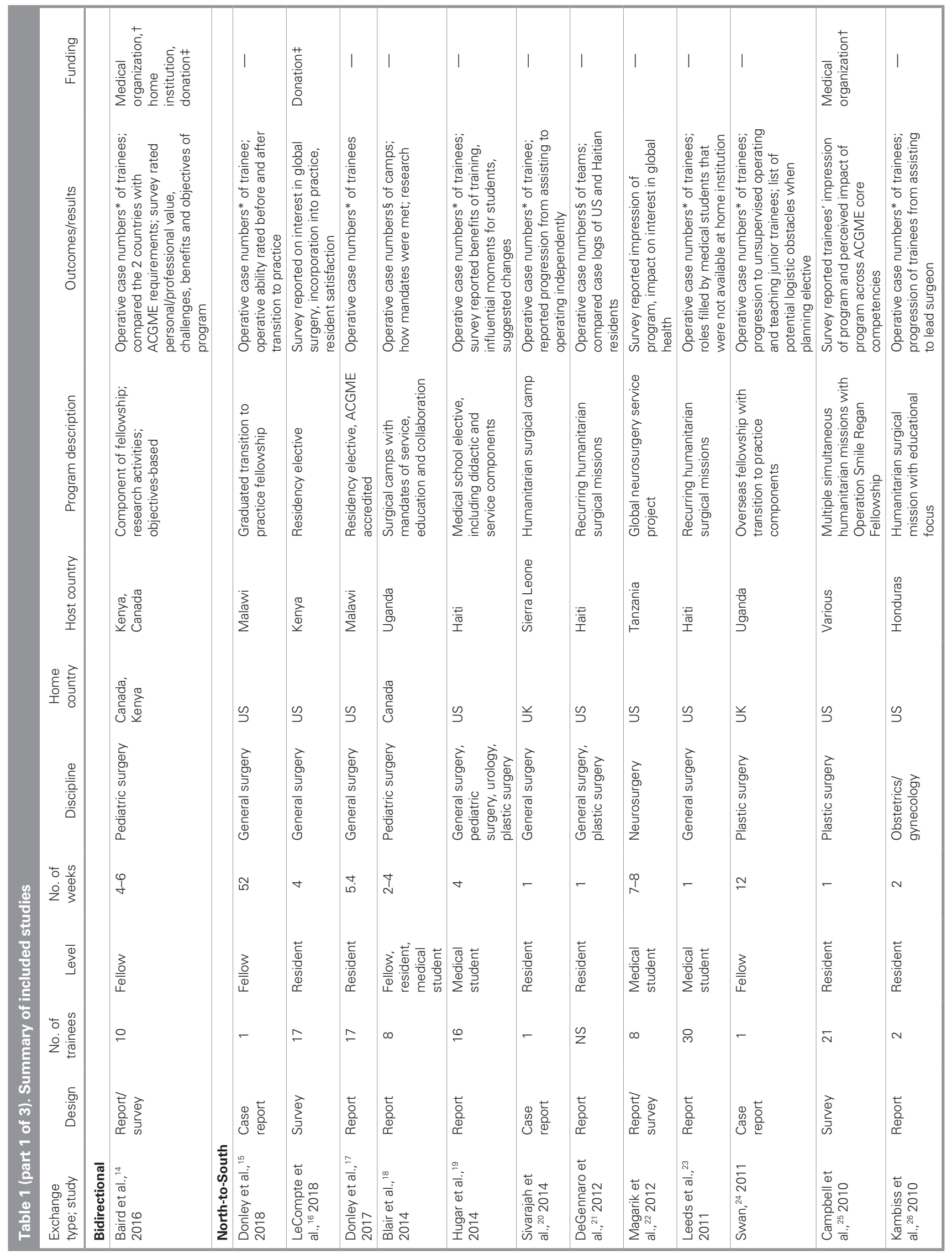




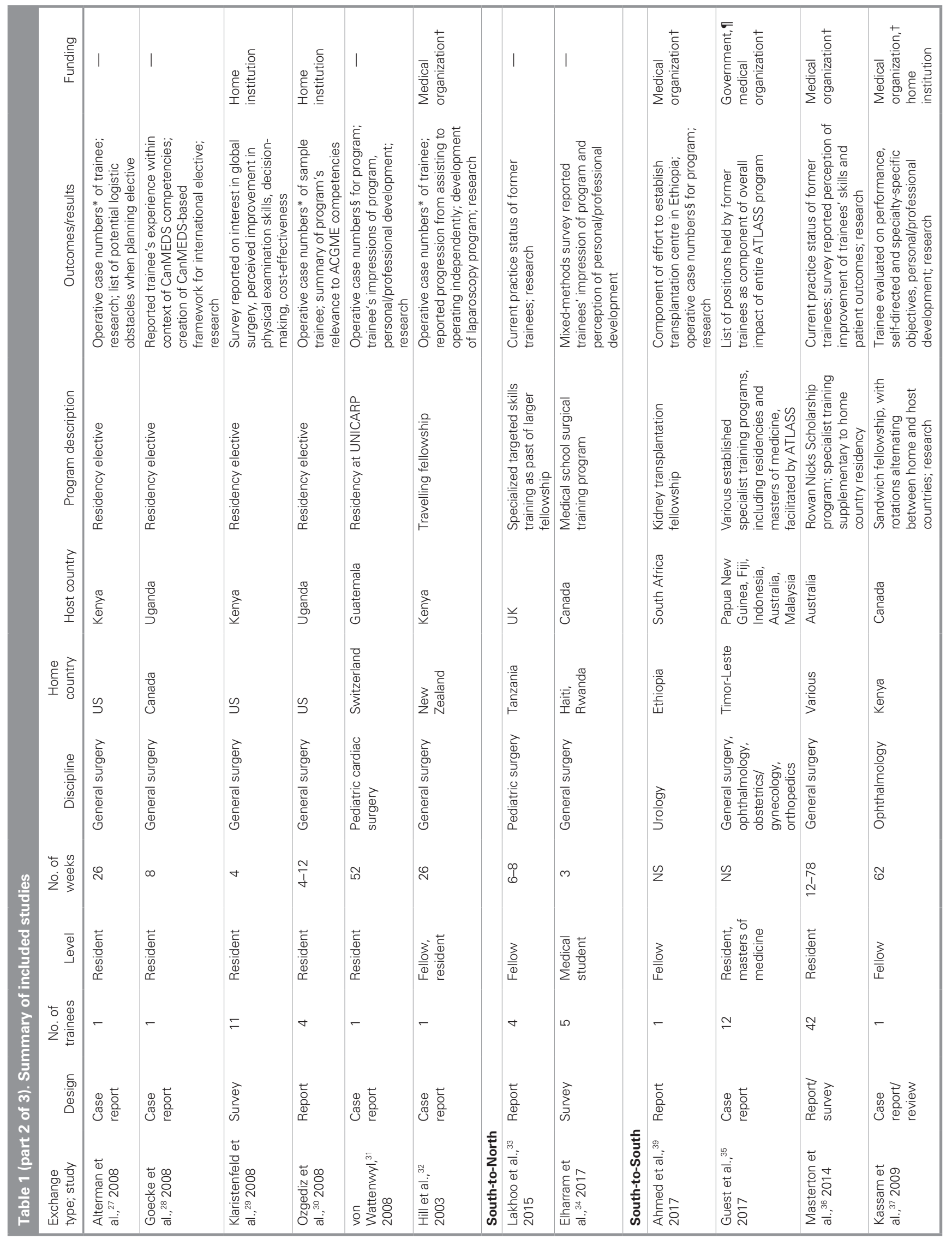




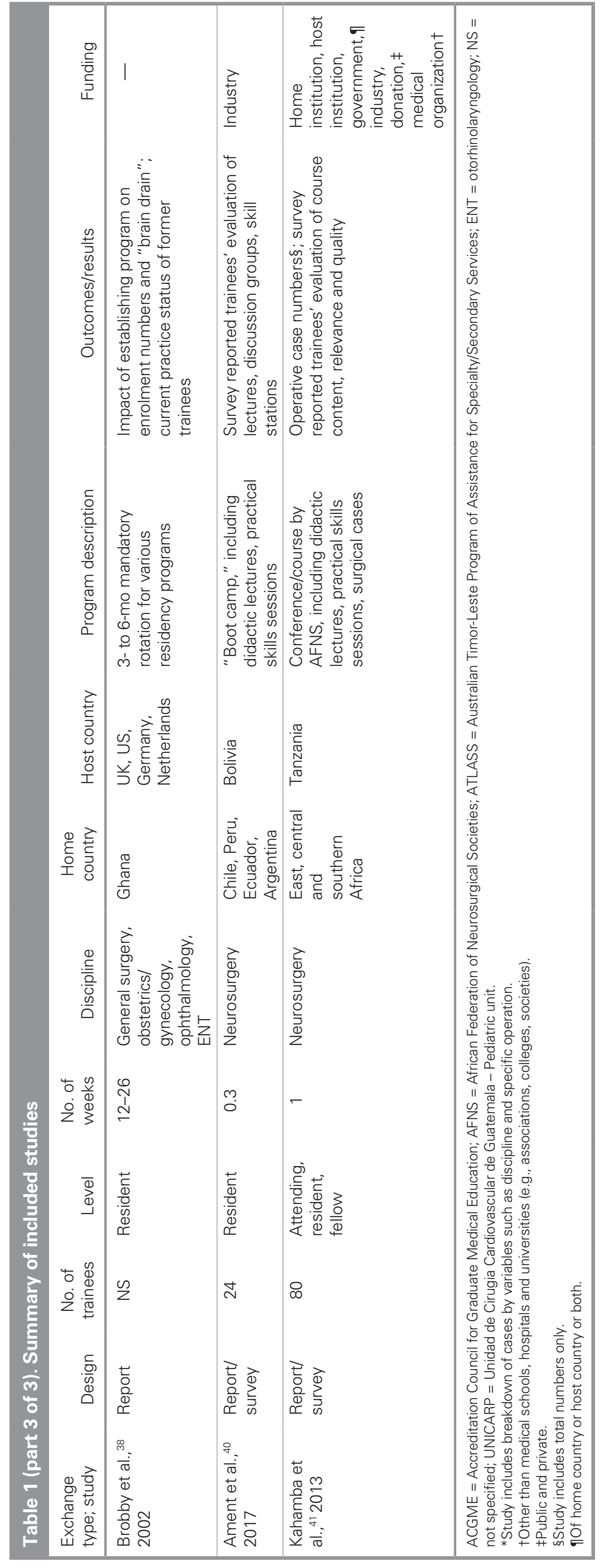

statement of aims (26 papers [93\%]), used appropriate qualitative methodology when necessary $(27$ [96\%]) and made a clear statement of their findings (26 [93\%]). However, only 11 publications (39\%) addressed the ethical implications of the study, whether it be the impact on the trainees, the survey respondents, or the involved LMICs and institutions. In addition, there was mention of the relationship between the researchers and participants in fewer than half of the studies (13 [46\%]), and only 15 publications $(54 \%)$ presented sufficiently rigorous analysis of the data.

Figure 4 illustrates the qualitative characteristics within individual studies. All but 3 publications had 3 or fewer questions answered as "Can't tell" or "No" on the Critical Appraisal Skills Programme Qualitative Checklist, which shows an overall high quality of qualitative evidence. The studies by $S_{w a n}{ }^{24}$ and von Wattenwyl ${ }^{31}$ both concerned a single trainee's experience and were more descriptive in nature, but both presented outcomes sufficient to meet our inclusion criteria. Similarly, Brobby and Ofosu-Barko ${ }^{38}$ presented data with little analysis or discussion of the impact of the study, but the article still met our inclusion criteria.

\section{Discussion}

Most of the educational exchanges between HICs and LMICs flowed North to South; only 1 report detailed a truly equitable bidirectional exchange of trainees. ${ }^{14}$ Exchanges were typically at the resident level, with most originating from North America and travelling to subSaharan Africa. The majority of exchanges involved the specialty of general surgery; nearly every surgical subspecialty reported at least 1 educational exchange. North-toSouth training experiences tended to be of relatively short duration (1-4 wk), be embedded within a surgical camp or mission, and generally lack a sustainable funding source. In contrast, South-to-North training exchanges tended to occur over a longer period and were more commonly supported by external organizations (e.g., the Rowan Nicks Scholarship program). Nearly all reported outcomes were positive, typically detailing subjective assessments after the exchange (qualitative surveys of trainee experience, performance evaluations). Few reports detailed quantitative metrics (e.g., case logs). Although nearly every subspecialty reported an example of an educational exchange, cardiac surgery was noticeable in its absence. Pediatric cardiac surgery in LMICs has been acknowledged as an important unmet need by the World Society for Pediatric and Congenital Heart Surgery, ${ }^{42}$ but conventional cardiac revascularization and valvular repair were unsurprisingly underrepresented, given the amount of resources required to support such a program.

The global surgical workforce has long been recognized as a key limitation to surgical capacity in LMICs. ${ }^{43,44}$ Although about half of the world's population lives in the global South, less than $20 \%$ of the world's surgical services 


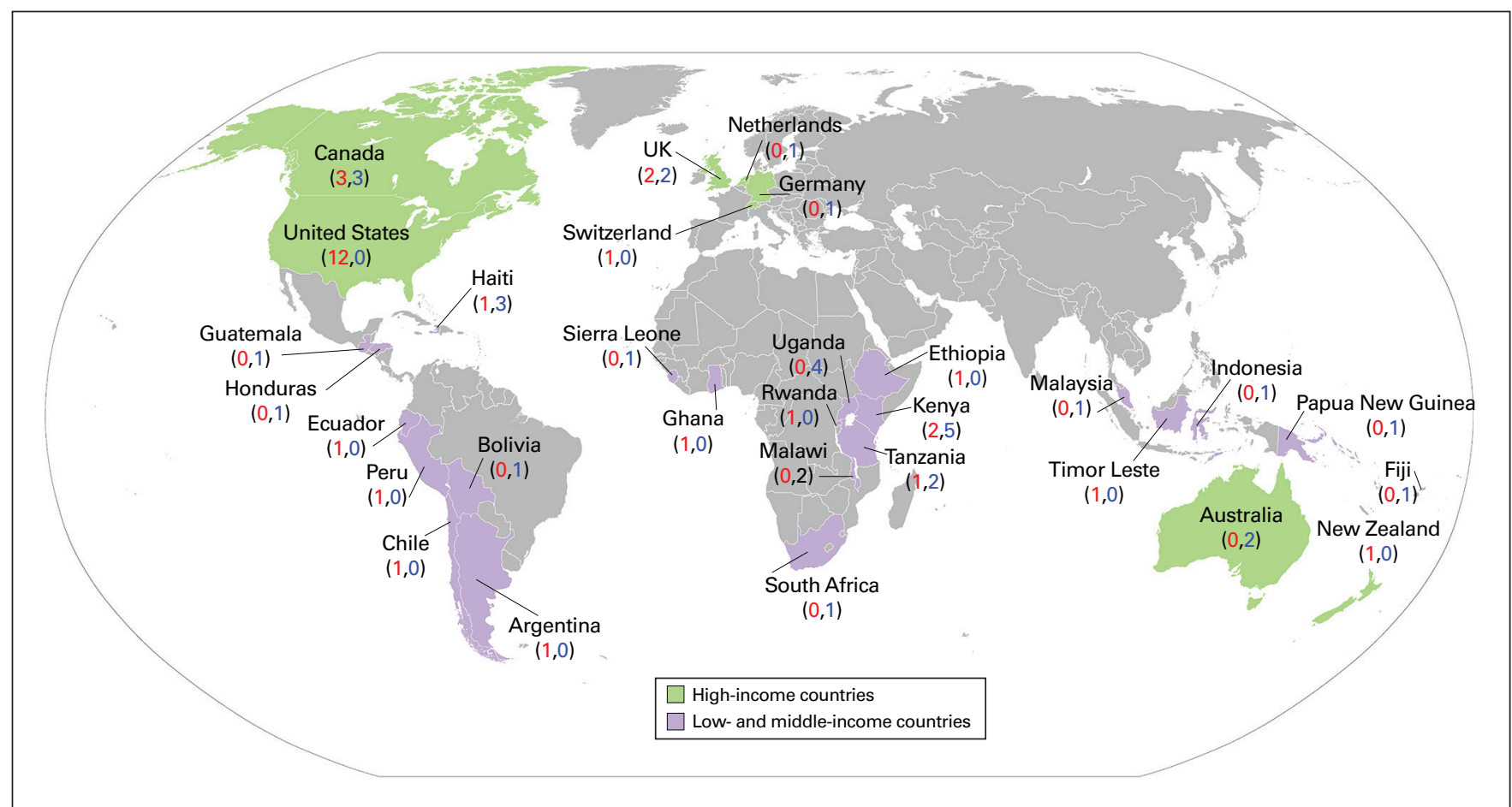

Fig. 2. World map showing all high-income countries, and low- and middle-income countries in included studies, and their roles in the described exchanges. Values in red = number of times as home country; values in blue = number of times as host country.

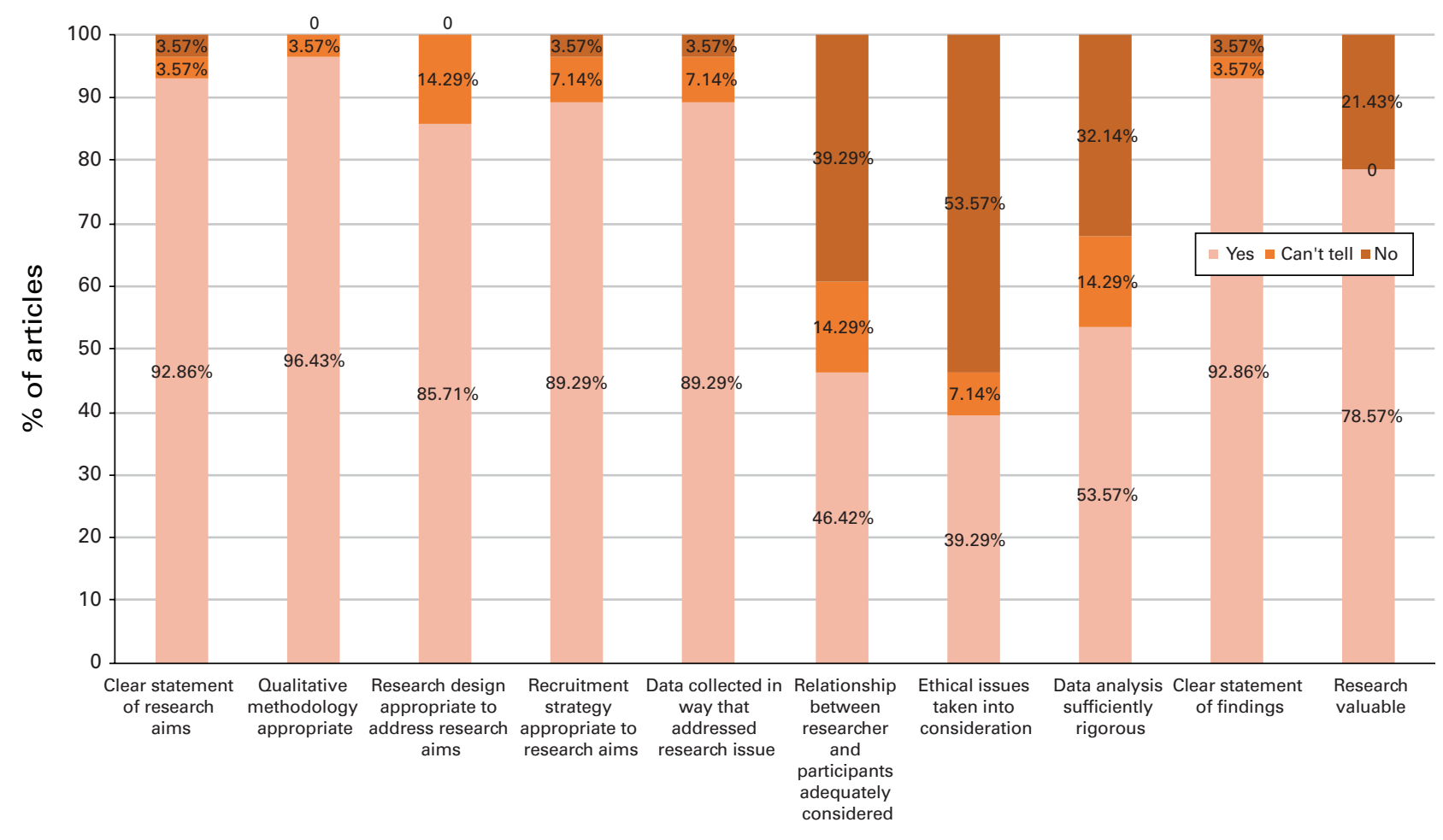

Question

Fig. 3. Critical appraisal across studies as determined with the Critical Assessment Skills Programme Qualitative Checklist. ${ }^{13}$ 


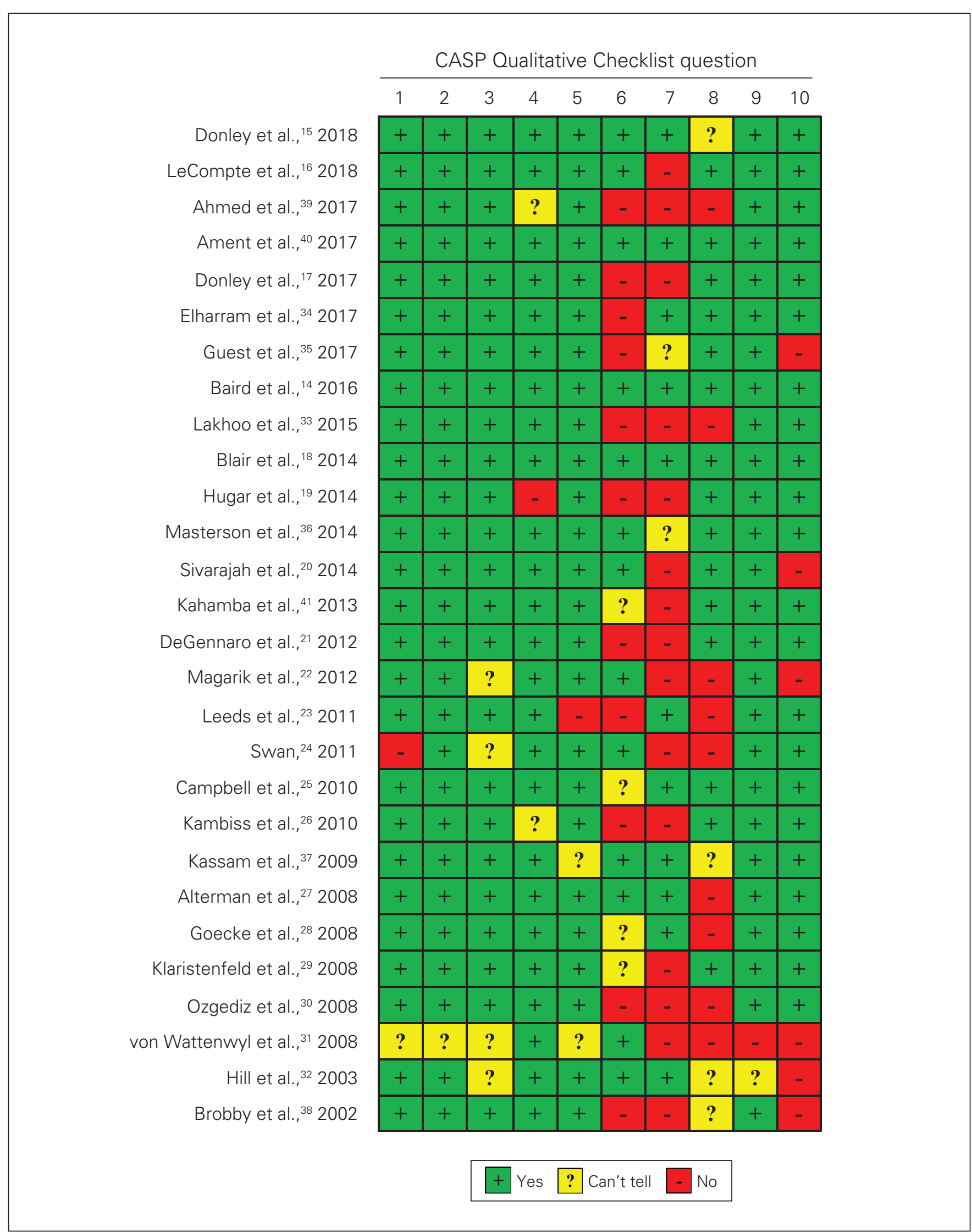

Fig. 4. Critical appraisal of individual studies as determined with the Critical Assessment Skills Programme Qualitative Checklist. ${ }^{13}$ 
are situated in these regions. Africa has been estimated to have 0.7 providers $/ 100000$ people, compared to 56.9/ 100000 in the global North. ${ }^{45}$ Task-shifting has been advocated by many institutions as a means of addressing the problem, ${ }^{46,47}$ but defining the limits of these practices, and ensuring appropriate training, supervision and referral systems generally remain works in progress. ${ }^{48}$ The training of surgeons to meet this need remains the aspirational aim of many engaged global surgical leaders; the question remains how best to accomplish the task. ${ }^{49}$

Recent reviews have evaluated the challenges of surgical training in LMICs, and have highlighted the variability in curricula and important differences when compared to HIC training programs. ${ }^{50,51}$ The College of Surgeons of East, Central and Southern Africa has emerged as an example of a successful multinational body overseeing postgraduate surgical education. Representing 9 countries and 320 million people, the college organizes membership and fellowship training programs in multiple surgical disciplines, with some trainees embarking on external rotations as part of their training. ${ }^{52}$ However, there is considerable variability in the exposure of trainees to opportunities outside their local training programs.

Authors have expressed concern about the possibility that exposure to HIC training may exacerbate the migration of a skilled surgical workforce from South to North. A 2013 survey of surgeons living in the United States but originating from LMICs identified professional factors as the biggest driver of migration. ${ }^{53}$ Although ongoing efforts to upscale local infrastructure and local educational opportunities may mitigate this phenomenon, it is unclear whether external educational experiences exacerbate the problem. Our review suggests that the "brain drain" may be less concerning than originally postulated: 4 studies of South-to-North exchanges provided information on where trainees ended up practising, and nearly all of them returned to practise in their home country. $33,36-38$ Those reports suggest that a format involving a short- to midterm exchange to a HIC, as part of a larger fellowship or residency in the home LMIC, does not increase the likelihood of brain drain. This is corroborated by a recent review of over 1000 College of Surgeons of East, Central and Southern Africa graduates, which reported that $93 \%$ of graduating trainees remained in Africa. ${ }^{54}$

Another common concern is that of surgical colonialism. Often, well-meaning programs or missions from HICs will prioritize the performance and education of their own trainees and surgeons, without investigating or addressing the surgical needs of the LMIC. ${ }^{2}$ Our findings lend credence to this claim: 13 of the 18 articles on Northto-South exchanges reported on the operative numbers and performance of HIC trainees, ${ }^{15,17-21,23,24,26,27,30-32}$ whereas only 2 of these programs stated that they educated and evaluated surgical trainees from the host LMIC. ${ }^{18,21}$ This indicates a large area for potential improvement, as training LMIC surgeons in their home countries is a wellestablished way to address the surgical workforce gap. ${ }^{2}$ Furthermore, there is evidence to suggest that incorporating teaching of local surgical trainees during short-term service missions is both effective and feasible. ${ }^{55}$ This concern can be addressed by ensuring that future North-toSouth programs, whether short-term or long-term, collaborate with LMIC institutions and allow them to dictate their own clinical and educational needs. ${ }^{2}$

Recent editorials have articulated a framework for training partnerships, focusing primarily on trainees from HIC environments. ${ }^{56-59}$ Barriers to involvement of trainees and attending physicians in global surgical experiences have been identified, all of which have been shown to be surmountable with a sustained commitment to partnership building. ${ }^{60}$ Many of the reports in our review lacked the perspective of the global South in properly matching educational goals to clinical needs. Our review also highlights that the majority of published educational exchanges failed to reference the ethics of inequalities between HICs and LMICs.

Many articles in our review reported primarily on the number of operations performed by trainees or on surveys of trainees' impressions of the exchange program. Although 9 of the 28 studies reported that trainees or their programs had produced research, , $^{14,18,27,28,31-33,36,37}$ and 4 reported on the current practice status of former trainees, ${ }^{33,36-38}$ none reported on the clinical outcomes of the patients treated during the exchange or the overall impact on the surgical disease burden in the area visited. Our review indicates that current authors are doing little to report on the value or impact of exchanges beyond the direct effect on trainees. This represents an important area for analysis in future publications on surgical trainee exchanges.

Moving forward, partnerships between HIC and LMIC institutions should aim to address the agency of the LMIC in the planning process, the host institution's educational and clinical needs, and the impact of the exchange, both positive and negative, on the host community.

As global surgery continues to shift toward a paradigm of long-term sustainable partnership, bidirectional exchanges may be one potential solution to some of the concerns that our review raises. Evidence from the bidirectional exchange suggests that, with proper planning, this model can assist in meeting the educational and clinical needs of trainees from both countries equitably and provide both groups with opportunities not available at their home program. ${ }^{14}$ In addition, this model can foster interest in global surgery in HIC trainees and help strengthen the LMIC surgical workforce. ${ }^{14}$

This systematic review represents an attempt to aggregate the collective experience of surgical exchanges bridging the North-South divide. Although it had relatively broad inclusion criteria, without linguistic or temporal 
restrictions, it may underrepresent reality "on the ground" for several reasons. Some manuscripts were unavailable owing to the limitations of electronic databasing, and some publications may have been missed during our search strategy. More important than these sources of misrepresentation, however, is the potential for a large number of educational exchanges to exist in the grey literature or simply go unpublished. This does not diminish their importance but does threaten the generalizability of our report, as the potential impact from unpublished exchanges on trainee and community outcomes cannot be assessed. This publication bias toward positive exchange experiences may overrepresent positive outcomes. Furthermore, our report does little to illuminate the value of these exchanges. There is little evidence that knowledge accrued from host country experiences will transfer to home countries or vice versa. Studying knowledge diffusion is a complex field, and most studies did not report data specific to the trainees and their individual accomplishments or benefits.

\section{Conclusion}

There exist a variety of surgical exchanges across disciplines, learner-types and host/home countries. Given the heterogeneity in existing publications, there is an increasing need to formalize these exchanges by means of clear goals and objectives, by prioritizing the proper matching of educational goals with local clinical needs, and by measuring the impact of these exchanges on patients and communities. As the drumbeat of global surgical needs becomes louder, future research will need to focus on establishing metrics of responsible educational partnerships for institutions and individuals from LMICs and HICs.

Affiliation: From the Division of Pediatric Surgery, University of British Colombia, Vancouver, BC.

Conflict of interest: None declared.

Contributors: T. Greive-Price and R. Baird designed the study. T. Greive-Price and H. Mistry acquired the data, which all authors analyzed and interpreted. All authors wrote and critically reviewed the article, and gave final approval of the article to be published.

\section{References}

1. Meara JG, Greenberg SLM. The Lancet Commission on Global Surgery Global surgery 2030: evidence and solutions for achieving health, welfare and economic development. Surgery 2015;157: 834-5.

2. Ng-Kamstra JS, Greenberg SLM, Abdullah F, et al. Global Surgery 2030: a roadmap for high income country actors. BM7 Glob Health 2016;1:e000011.

3. Haider A, Scott JW, Gause CD, et al. Development of a unifying target and consensus indicators for global surgical systems strengthening: proposed by the Global Alliance for Surgery, Obstetric, Trauma, and Anaesthesia Care (the G4 Alliance). World F Surg 2017;41:2426-34.

4. Goodman LF, St-Louis E, Yousef Y, et al. The Global Initiative for Children's Surgery: optimal resources for improving care. Eur 7 Pediatr Surg 2018;28:51-9.
5. Watters DA, Guest GD, Tangi V, et al. Global surgery system strengthening: it is all about the right metrics. Anesth Analg 2018; 126:1329-39.

6. Yousef Y, Lee A, Ayele F, et al. Delayed access to care and unmet burden of pediatric surgical disease in resource-constrained African countries. F Pediatr Surg 2019;54:845-53.

7. Muñiz SA, Lang RW 3rd, Falcon L, et al. Preparing global trauma nurses for leadership roles in global trauma systems. 7 Trauma Nurs 2017;24:306-11.

8. Merchant AI, Walters CB, Valenzuela J, et al. Creating a global acute care surgery fellowship to meet international need. F Surg Educ 2017;74:780-6.

9. Barreiro G, Mellin-Olsen J, Gore-Booth J. The role of the WFSA in reaching the goals of the Lancet Commission on Global Surgery. Anesth Analg 2018;126:1400-4.

10. Macpherson L, Collins M. Training responsibly to improve global surgical and anaesthesia capacity through institutional health partnerships: a case study. Trop Doct 2017;47:73-7.

11. Moher D, Liberati A, Tetzlaff J, et al Preferred reporting items for systematic reviews and meta-analyses: the PRISMA Statement. PLoS Med 2009;6:e1000097.

12. The World Bank. World Bank Country and Lending Groups [Internet]. Available: https://datahelpdesk.worldbank.org/knowledgebase/ articles/906519 (accessed 2019 Nov. 21).

13. Qualitative Checklist CASP. [Internet]. Oxford (UK): Critical Appraisal Skills Programme. Available: https://casp-uk.net/casp -tools-checklists/ (accessed 2018 July 12).

14. Baird R, Poenaru D, Ganey M, et al. Partnership in fellowship: comparative analysis of pediatric surgical training and evaluation of a fellow exchange between Canada and Kenya. 7 Pediatr Surg 2016;51: 1704-10.

15. Donley DK, Graybill CK, Fekadu A, et al. Transition to practice: a global surgery approach. 7 Surg Educ 2018;75:392-6.

16. LeCompte MT, Goldman C, Tarpley JL, et al. Incorporation of a global surgery rotation into an academic general surgery residency program: impact and perceptions. World F Surg 2018;42:2715-24.

17. Donley DK, Graybill CK, Fekadu A, et al. Loma Linda global surgery elective: first 1000 cases. 7 Surg Educ 2017;74:934-8.

18. Blair GK, Duffy D, Birabwa-Male D, et al. Pediatric surgical camps as one model of global surgical partnership: a way forward. 7 Pediatr Surg 2014;49:786-90.

19. Hugar LA, McCullough CM, Quinn ME, et al. Scaling up shortterm humanitarian surgery: a global surgery elective for senior medical students. 7 Surg Educ 2014;71:871-7.

20. Sivarajah V, Shanmugam M, Tuckey E, et al. Surgical training during a voluntary medical/surgical camp in Sierra Leone. Bull Royal Coll Surg Engl 2014;96:350-2.

21. DeGennaro VA Jr, DeGennaro VA, Kochhar A, et al. Accelerating surgical training and reducing the burden of surgical disease in Haiti before and after the earthquake. 7 Craniofac Surg 2012;23:2028-32.

22. Magarik J, Kavolus J, Louis R. An American medical student's experience in global neurosurgery: both in their infancy. World Neurosurg 2012;77:28-31.

23. Leeds IL, Creighton FX, Wheatley MA, et al. Intensive medical student involvement in short-term surgical trips provides safe and effective patient care: a case review. BMC Res Notes 2011;4:317.

24. Swan MC. Plastic surgery fellowships in the developing world: a Ugandan experience. Ann Plast Surg 2011;67:326-8.

25. Campbell A, Sherman R, Magee WP. The role of humanitarian missions in modern surgical training. Plast Reconstr Surg 2010;126:295-302.

26. Kambiss S, Dooley Y, Gonzalez-Garcia H, et al. Non-oral poster 33: Teaching residents the repair of obstetric fistulae: our mission experience in Honduras. Female Pelvic Med Reconstr Surg 2010;16:S30.

27. Alterman DM, Goldman MH. International volunteerism during general surgical residency: a resident's experience. 7 Surg Educ 2008; 65:378-83. 
28. Goecke ME, Kanashiro J, Kyamanywa P, et al. Using CanMEDS to guide international health electives: an enriching experience in Uganda defined for a Canadian surgery resident. Can 7 Surg 2008;51: $289-95$.

29. Klaristenfeld DD, Chupp M, Cioffi WG, et al. An international volunteer program for general surgery residents at Brown Medical School: the Tenwek Hospital Africa experience. 7 Am Coll Surg 2008; 207:125-8

30. Ozgediz D, Wang J, Jayaraman S, et al. Surgical training and global health: initial results of a 5 -year partnership with a surgical training program in a low-income country. Arch Surg 2008;143:860-5.

31. von Wattenwyl $R$. Ten years after the initiation of congenital heart surgery in Guatemala: observations after a one year fellowship in the pediatric cardiac unit in a low income country. Thorac Cardiovasc Surg 2008;56:205-9.

32. Hill AG, Woodfield JC. Training outside of the box. ANZ 7 Surg 2003;73:881-3.

33. Lakhoo K, Msuya D. Global health: a lasting partnership in paediatric surgery. Afr 7 Paediatr Surg 2015;12:114-8.

34. Elharram M, Dinh T, Lalande A, et al. Global health values of a multidirectional near peer training program in surgery, pathology, anatomy, research methodology, and medical education for Haitian, Rwandan, and Canadian medical students. Ann Glob Health 2017;83: 274-80.

35. Guest GD, Scott DF, Xavier JP, et al. Surgical capacity building in Timor-Leste: a review of the first 15 years of the Royal Australasian College of Surgeons-led Australian Aid programme. ANZ 7 Surg 2017;87:436-40.

36. Masterton JP, Moss D, Korin SJ, et al. Evaluation of the mediumterm outcomes and impact of the Rowan Nicks Scholarship Programme. ANZ 7 Surg 2014;84:110-6.

37. Kassam F, Damji KF, Kiage D, et al. The Sandwich fellowship: a subspecialty training model for the developing world. Acad Med 2009;84:1152-60.

38. Brobby GW, Ofosu-Barko FO. Developing appropriate communitybased postgraduate training in a developing country. Educ Health (Abingdon) 2002;15:3-9.

39. Ahmed MM, Bekele M, Abebe E, et al. Programmatic aspects of initiating kidney transplantation in Ethiopia. Transplantation 2017; 101:S94.

40. Ament JD, Kim T, Gold-Markel J, et al. Planning and executing the neurosurgery boot camp: the Bolivia experience. World Neurosurg 2017;104:407-10.

41. Kahamba JF, Assey AB, Dempsey RJ, et al. The second African Federation of Neurological Surgeons course in the East, Central, and Southern Africa region held in Dar es Salaam, Tanzania, January 2011. World Neurosurg 2013;80:255-9.

42. Nguyen N, Leon-Wyss J, Iyer KS, et al. Paediatric cardiac surgery in low-income and middle-income countries: a continuing challenge. Arch Dis Child 2015;100:1156-9.
43. Ozgediz D, Galukande M, Mabweijano J, et al. The neglect of the global surgical workforce: experience and evidence from Uganda. World f Surg 2008;32:1208-15.

44. Hoyler M, Finlayson SR, McClain CD, et al. Shortage of doctors, shortage of data: a review of the global surgery, obstetrics, and anesthesia workforce literature. World 7 Surg 2014;38:269-80.

45. Holmer H, Lantz A, Kunjumen T, et al. Global distribution of surgeons, anaesthesiologists, and obstetricians. Lancet Glob Health 2015; 3:S9-11.

46. Vaz F, Bergström S, Vaz ML, et al. Training medical assistants for surgery. Bull World Health Organ 1999;77:688-91.

47. Federspiel F, Mukhopadhyay S, Milsom P, et al. Global surgical and anaesthetic task shifting: a systematic literature review and survey. Lancet 2015;385:S46.

48. Chu K, Rosseel P, Gielis P, et al. Surgical task shifting in subSaharan Africa. PLoS Med 2009;6:e1000078.

49. Watters DA, Bayley AC. Training doctors and surgeons to meet the surgical needs of Africa. Br Med 7 (Clin Res Ed) 1987; 295:761-3

50. Rickard J. Systematic review of postgraduate surgical education in low- and middle-income countries. World 7 Surg 2016;40: 1324-35.

51. Klein R, Park A. Surgical training in low-resource settings. In: Park A, Price R, editors. Global surgery: the essentials. New York: Springer Publishing; 2017;51-67.

52. Kakande I, Mkandawire N, Thompson MI. A review of surgical capacity and surgical education programmes in the COSECSA region. East Cent Afr 7 Surg 2011;16:6-34.

53. Hagander LE, Hughes CD, Nash K, et al. Surgeon migration between developing countries and the United States: train, retain, and gain from brain drain. World 7 Surg 2013;37: 14-23.

54. Hutch A, Bekele A, O'Flynn E, et al. The brain drain myth: retention of specialist surgical graduates in east, central and southern Africa, 1974-2013. World 7 Surg 2017;41: 3046-53.

55. McCullough M, Campbell A, Siu A, et al. Competency-based education in low resource settings: development of a novel surgical training program. World 7 Surg 2018;42:646-51.

56. Baird R, Pandya K, Lal DR, et al. Regarding global pediatric surgery training opportunities. F Pediatr Surg 2018;53:1256-8.

57. Petroze RT, Castle SL, Radulescu A, et al. An appeal from fellows. $\mathcal{F}$ Pediatr Surg 2018;53:1259-60.

58. Ozgediz D. Global experiences in fellowship training: a valuable opportunity to match competencies with contemporary priorities and needs. 7 Pediatr Surg 2018;53:1254-5.

59. O’Neill JA Jr, Hansen EN, Nyagetuba JM, et al. A plan for surgical education in low- and middle-income countries. 7 Trauma Acute Care Surg 2017;83:784-7.

60. Cheung M, Healy JM, Hall MR, et al. Assessing interest and barriers for resident and faculty involvement in global surgery. I Surg Educ 2018; 75:49-57. 